\title{
CYP2D6 basic genotyping as a potential tool to improve the antiemetic efficacy of ondansetron in prophylaxis of postoperative nausea and vomiting
}

\author{
Przemysław A. Niewiński ${ }^{1, A, D}$, Robert Wojciechowski ${ }^{2, B}$, Marek Śliwiński ${ }^{2, B}$, Magdalena E. Hurkacz, ${ }^{1, C, C, F}$, \\ Krystyna Głowacka ${ }^{1, B}$, Krystyna Orzechowska-Juzwenko ${ }^{1, A, E}$, Anna K. Wiela-Hojeńska ${ }^{1, A, E, F}$ \\ 'Department of Clinical Pharmacology, Faculty of Pharmacy with Division of Laboratory Diagnostics, Wroclaw Medical University, Poland \\ ${ }^{2}$ Department of Anesthesiology and Intensive Therapy, Faculty of Medicine, Wroclaw Medical University, Poland \\ A - research concept and design; $\mathrm{B}$ - collection and/or assembly of data; $\mathrm{C}$ - data analysis and interpretation; \\ $D$ - writing the article; $E$ - critical revision of the article; $F$ - final approval of the article
}

Address for correspondence

Magdalena E. Hurkacz

E-mail:magdalena.hurkacz@umed.wroc.pl

Funding sources

None declared

Conflict of interest

None declared

Received on 0ctober 18, 2016

Reviewed on February 21, 2017

Accepted on March 13, 2017

\begin{abstract}
Background. Postoperative nausea and vomiting (PONV) is a common complication after anesthesia and surgery. Ondansetron is one of the most widely used drugs in the prophylaxis of PONV and is extensively metabolized in humans. In vitro metabolism studies have shown that ondansetron is a substrate for human hepatic cytochrome P450 enzymes. The cytochrome P450 (human hepatic cytochrome (CYP)) 206 inhibitor quinidine reduced in vitro hydroxylation of ondansetron, which indicates the important role of CYP2D6 in ondansetron metabolism. Genotyping these alleles allows the prediction of the extensive metabolizer (EM) and poor metabolizer (PM) phenotypes with approx. 90-96\% accuracy.
\end{abstract}

Objectives. The aim of our study was to evaluate whether the pharmacological prevention of PONV with ondansetron depends on the most common CYP2D6 alleles (CYP206*1,*3,*4, ${ }^{*}$, and NXN (multiplication gene)).

Material and methods. Genotyping for the defective CYP2D6*3, CYP2D6*4 and CYP2D $6 * 5$ alleles among 93 surgical female patients was performed by polymerase chain reaction amplification and restriction fragment length polymorphism (PCR-RFLP).

Results. The genetically defined EMs and ultrarapid metabolizers (UMs) of CYP2D6 had a statistically significant $(p<0.02)$ higher frequency of nausea and vomiting after strumectomy $(33.3 \%)$ than intermediate metabolizers (IMs) (10.3\%) and PMs (0\%). The relative risk (odds ratio (OR)) of PONV occurrence was 5 times higher for EMs/UMs than IMs/PMs.

Conclusions. Our results suggest that PONV treatment with ondansetron could be improved by basic, widely available and inexpensive PCR-RFLP genetic tests.

Key words: CYP2D6, ondansetron, postoperative nausea and vomiting

DOI

10.17219/acem/69451

\section{Copyright}

Copyright by Author(s)

This is an article distributed under the terms of the

Creative Commons Attribution Non-Commercial License

(http://creativecommons.org/licenses/by-nc-nd/4.0/) 


\section{Introduction}

Postoperative nausea and vomiting (PONV) is a common complication after anesthesia and surgery. Pain, nausea and vomiting are frequently listed by patients as their most pressing perioperative concerns. With the change in emphasis from inpatient hospitals to outpatient hospitals and office-based medical/surgical settings, there has been an increased interest in the problem of PONV. The etiology and consequences of PONV are complex and multifactorial, with patient-, medicine-, and surgeryrelated factors; the important predictors are female gender, a history of PONV and a history of motion sickness. The vomiting center can be triggered by the activation of dopamine, serotonin (type 3), histamine (type 1), and muscarinic cholinergic receptors in the chemoreceptor trigger zone and the nucleus tractus solitarius, as well as acetylcholine receptors in the vestibular apparatus, vagal afferents from the periphery and the endocrine environment. Currently, the overall incidence of PONV is estimated to be $25-30 \% .^{1-3}$

Ondansetron is one of the most widely used drugs in the prophylaxis of PONV. ${ }^{4}$ While its mechanism of action has not been fully characterized, ondansetron is not a dopamine-receptor antagonist. Serotonin receptors of 5-HT3 type are present both peripherally on vagal nerve terminals and centrally in the chemoreceptor trigger zone of the area postrema. It is not certain whether ondansetron's antiemetic action is mediated centrally, peripherally or in both sites. Approximately $95 \%$ of ondansetron is extensively metabolized in humans: only $5 \%$ of a radiolabeled dose is recovered from the urine in the form of the parent compound. The primary metabolic pathway is hydroxylation on the indole ring, followed by subsequent glucuronide or sulfate conjugation. Although some non-conjugated metabolites have pharmacological activity, these are not found in plasma at concentrations likely to significantly contribute to the biological activity of ondansetron. ${ }^{5,6}$

In vitro metabolism studies have shown that ondansetron is a substrate for human hepatic cytochrome (CYP) P450 enzymes, including CYP1A2, CYP2D6, CYP3A4, and CYP2E1. According to Fisher et al. as well as Janicki and Sugino, the CYP2D6 inhibitor quinidine reduced the in vitro hydroxylation of ondansetron, which indicates the important role of CYP2D6 in ondansetron metabolism. 5,7,9 The in vitro study by Sanwald et al. confirmed that ondansetron is both CYP2D6- and CYP2E1-dependent. ${ }^{8}$

The enzymes belonging to the cytochrome P450 family, especially CYP2D6, have an important role in the metabolism of over $25 \%$ of drugs. ${ }^{9,10}$ Tricyclic antidepressants, neuroleptics, cardiologic drugs, and opioids in particular show wide interindividual and interethnic variability in both therapeutic efficacy and adverse effects. ${ }^{11-14}$ The polymorphism of CYP2D6 is relatively well-known and more than 20 mutations of the CYP2D6 gene have been described. CYP2D6*3 (formerly A-mutation), $C Y P 2 D 6 * 4$ (formerly B-mutation) and $C Y P 2 D 6 * 5$ (gene deletion, formerly D-mutation) are the most common non-functional CYP2D6 alleles. ${ }^{15}$ Therefore, the genotyping of these alleles allows the prediction of the extensive metabolizer (EM) and poor metabolizer (PM) phenotypes with about $90-96 \%$ accuracy. ${ }^{16,17}$

\section{Objectives}

The aim of our study was to evaluate whether the efficacy of antiemetic treatment with ondansetron is influenced by mutations of the most common CYP2D6 genotype, hypothesizing that extensive metabolizers of this drug are at risk of being undertreated. This study sought to investigate whether the efficacy of antiemetic treatment with ondansetron could be improved by adjusting for the most common CYP2D6 genotype, using basic, widely available and inexpensive (less than $\$ 100$ ) polymerase chain reaction (PCR), and polymerase chain reaction amplification and restriction fragment length polymorphism (PCR-RFLP) tests.

\section{Material and methods}

\section{Subjects}

The study was performed on a group of 93 women with thyroid diseases (neutral struma nodosa and struma nodosa toxica), hospitalized for thyroid gland surgery (strumectomy). They were patients of the $1^{\text {st }}$ Department of Surgery, Wroclaw Medical University, Poland. Their ages ranged from 18 to 84 years, with a mean of 49.85 years (standard deviation (SD): 14.41). None had significant renal, hepatic or cardiovascular disease, insulin-dependent diabetes, chronic obstructive pulmonary disease, or cerebral vascular accident. Patients were excluded if any potential CYP2D6 inhibitor, such as other agents metabolized by isoenzyme CYP2D6, i.e., beta-adrenergic blocking agents, tricyclic antidepressants, antiarrhythmic Ic class drugs, debrisoquine, codeine, or dextromethorphan, had been administered 14 days prior to surgery.

Informed consent was obtained in every case. The protocol for the study was approved by the Bioethics Committee of the Wroclaw Medical University, Poland.

\section{Study design}

Ondansetron was administered to patients orally in doses of $8 \mathrm{mg}$ before surgery, for the prevention of PONV.

\section{Genotyping methods}

DNA was arranged from leukocytes extracted from peripheral blood. Genotyping for the defective CYP2D6*3, $C Y P 2 D 6^{*} 4$ and $C Y P 2 D 6 * 5$ alleles (a single base-pair deletion in exon 5 for $C Y P 2 D 6 * 3$, G1934 to A point mutation for $C Y P 2 D 6 * 4$, and a gene deletion for $C Y P 2 D 6 * 5)$ was performed by PCR-RFLP method, based on the method 
described by Smith et al. ${ }^{18}$ For the CYP2D6*3 mutation, PCR was performed using the primers E - GATGAGCTGCTAACTGAGCCC and F - CCGAGAGCATACTCGGGAC. For the CYP2D6*4 mutation, PCR was performed using the primers C-GCCTTCGCCAACCACTCCG and D - AAATCCTGCTCTTCCGAGGC.

The PCR amplification product (after verification by electrophoresis in $2 \%$ agarose gel) was identified by the RFLP method. The restriction enzymes BstNl (for $C Y$ $P 2 D 6 * 4$ mutation) and HpaII (for CYP2D6*3 mutation) were used. The separation of restriction products was performed by electrophoresis in 3\% agarose gel with the addition of ethidium bromide. The results were observed under UV light and recorded in a graphic form.

A lack of $C Y P 2 D 6$ amplification, suggesting $C Y P 2 D 6$ gene deletion, was confirmed by an external laboratory (Research Institute of Medicinal Plants, Poznań, Poland).

Alleles not carrying CYP2D6*3, CYP2D6*4 or CYP2D6*5 were classified as $C Y P 2 D 6^{*} 1$ (wild-type) alleles using this method. Dominant homozygotes with 2 wild-type alleles $(w t / w t-C Y P 2 D 6 * l / C Y P 2 D 6 * 1)$ were classified as CYP2D6 EMs. Heterozygotes with 1 wild-type allele $(w t-C Y P 2 D 6 * 1)$ and $1 C Y P 2 D 6 * 3, C Y P 2 D 6 * 4$ or $C Y P 2 D 6 * 5$ allele were classified as $C Y P 2 D 6$ intermediate metabolizers (IMs). Recessive homozygotes, carrying 2 alleles with a mutation (CYP2D6*3 or CYP2D6*4) were classified as CYP2D6 PMs.

To identify individuals carrying multiple $C Y P 2 D 6$ genes (CYP2D6*NxN), CYP2D6 multiplication assays were performed according to the method of Lovlie et al., modified by Steijns and van der Weide. ${ }^{19,20}$ Expand Long-PCR was carried out using an Expand Long Template PCR System kit (Hoffmann-La Roche, Basel, Switzerland). With the primer combination of CYP-17f (5'-TCCCCCACTGACCCAACTCT-3') and CYP-32r (5'-CACGTGCAGGGCACCTAGAT-3'), a 3.6-kb PCR fragment amplified from the CYP2D6-CYP2D6 region was observed in subjects having multiple alleles of the $C Y P 2 D 6$ gene.

The number of nausea and vomiting episodes was counted, and PONV intensity was evaluated with the Postoperative Nausea and Emetic Scale (PNES) (Table 1) during the first $5 \mathrm{~h}$ after surgery.

The PNES results were calculated immediately after surgery $(0 \mathrm{~h})$, during the $1^{\text {st }}$ hour $(1 \mathrm{~h})$ and during the next $4 \mathrm{~h}(5 \mathrm{~h})$.

Table 1. The Postoperative Nausea and Emetic Scale (PNES)

\begin{tabular}{|c|c|c|}
\hline \multicolumn{2}{|c|}{$\begin{array}{l}\text { Postoperative Nausea } \\
\text { and Emetic Scale (PNES) }\end{array}$} & Value [points] \\
\hline \multirow{4}{*}{ Nausea } & absent & 0 \\
\hline & slight & 1 \\
\hline & medium & 2 \\
\hline & heavy & 3 \\
\hline \multirow{3}{*}{ Vomiting } & 1 episode & 4 \\
\hline & 2-3 episodes & 5 \\
\hline & 4 or more episodes & 6 \\
\hline
\end{tabular}

\section{Statistical analysis}

The statistical analysis of the results was performed using the $\chi^{2}$ test, with or without Yates's correction, and the Fisher's exact test. For the statistical analysis of the antiemetic efficacy of ondansetron among different CYP2D6 genotype groups, the relative risk (odds ratio (OR)) was calculated. The pharmacoeconomic value of genotyping was determined by calculating the Number Needed to Diagnose (NND): the number of people who should be screened in order to prevent 1 adverse end point.

Statistical software used included STATISTICAv. 10 and 12 (StatSoft Inc., Tulsa, USA) and RelRisk v. 0.8 (author's own software, Wrocław, Poland).

\section{Results}

The frequency of the CYP2D6*1,CYP2D6*3, CYP2D6*4, and $C Y P 2 D 6 * N x N$ alleles among the 93 genotyped patients was $79.0 \%, 1.1 \%, 18.8 \%$, and $1.1 \%$, respectively. Fifty-nine patients $(63.4 \%)$ were homozygous for the wild-type $C Y$ P2D6 allele (CYP2D6*1/*1) and were classified as EMs. One woman $(1.1 \%)$ was a carrier of $C Y P 2 D 6$ multiplication $(C Y P 2 D 6 * 1 / N x N)$ and was classified as an ultrarapid metabolizer (UM). Among 29 heterozygous women (31.2\%) predicted to be IMs, 27 individuals $(29.0 \%)$ carried the CYP2D6*1/*4 genotype (B-mutation), while 2 (2.2\%) carried the $C Y P 2 D 6 * 1 / * 3$ genotype (A-mutation). A group of 4 carriers of CYP2D6-deficient genes (4.3\%) were homozygous individuals carrying 2 nonfunctional B alleles (CYP2D6*4/*4 genotype).

Out of all 93 patients, 23 (24.7\%) experienced nausea and vomiting. Sixty subjects genetically defined as EMs and UMs of CYP2D6 had statistically significant higher frequency of nausea and vomiting (Yates corrected $\chi^{2}=5.48, \mathrm{p}<0.02$, Fisher's exact test $\mathrm{p}<0.011)$ than IMs and PMs. As many as 20 of the 60 EMs and UMs (33.3\%) experienced PONV, while only 3 of the 29 IMs (10.3\%) and none of the 4 PMs (0\%) reported this condition (Fig. 1).

Moreover, PONV intensity (measured by the PNES) was higher among EMs and UMs (mean PNES value $=3.97$ ) than among IMs and PMs (mean PNES value $=0.19$ ). Detailed information regarding the frequency and intensity of PONV immediately after surgery $(0 \mathrm{~h})$, during the $1^{\text {st }}$ hour $(1 \mathrm{~h})$ and during the next $4 \mathrm{~h}(5 \mathrm{~h})$ is shown in Table 2 .

The relative risk (OR) of PONV occurrence was 5 times higher (confidence interval $(\mathrm{CI})=1.36-18.39, \mathrm{p}<0.02)$ for EMs and UMs than for IMs and PMs. The relative risk was especially higher immediately after surgery $(\mathrm{OR}=4.18, \mathrm{CI}=1.02-10.47$, $\mathrm{p}<0.04)$, compared with the $1^{\text {st }}$ hour $(\mathrm{OR}=2.29, \mathrm{CI}=0.60-$ 8.77 , non-significant (NS)) or the period of $1-5 \mathrm{~h}$ after surgical treatment $(\mathrm{OR}=3.30, \mathrm{CI}=0.382-28.59$, NS).

The NND - the number of people who should be screened in order to prevent 1 episode of PONV - was 3.35 $(\mathrm{CI}=2.35-20.85)$, which suggests a relatively high pharmacoeconomic value for CYP2D6 genotyping. 
Table 2. Postoperative nausea and vomiting (PONV) frequency and intensity (measured by the Postoperative Nausea and Emetic Scale [PNES]) in patients during the $1^{\text {st }} 5 \mathrm{~h}$ after surgical treatment

\begin{tabular}{|c|c|c|c|c|c|c|}
\hline \multirow[b]{2}{*}{ Genotype } & \multicolumn{2}{|c|}{$\mathrm{O}$ h after surgery } & \multicolumn{2}{|c|}{$1 \mathrm{~h}$ after surgery } & \multicolumn{2}{|c|}{$5 \mathrm{~h}$ after surgery } \\
\hline & $\begin{array}{c}\text { number of } \\
\text { episodes }\end{array}$ & mean PNES points & $\begin{array}{l}\text { number of } \\
\text { episodes }\end{array}$ & mean PNES points & $\begin{array}{c}\text { number of } \\
\text { episodes }\end{array}$ & mean PNES points \\
\hline UMs and EMs $(n=60)$ & 17 & 5.10 & 11 & 4.70 & 5 & 2.1 \\
\hline IMs $(n=29)$ & 3 & 0.26 & 2 & 0.20 & 1 & 0.1 \\
\hline PMs $(n=4)$ & 0 & 0 & 0 & 0 & 0 & 0 \\
\hline
\end{tabular}

UMs - ultrarapid metabolizers; EMs - extensive metabolizers; IMs - intermediate metabolizers; PMs - poor metabolizers.

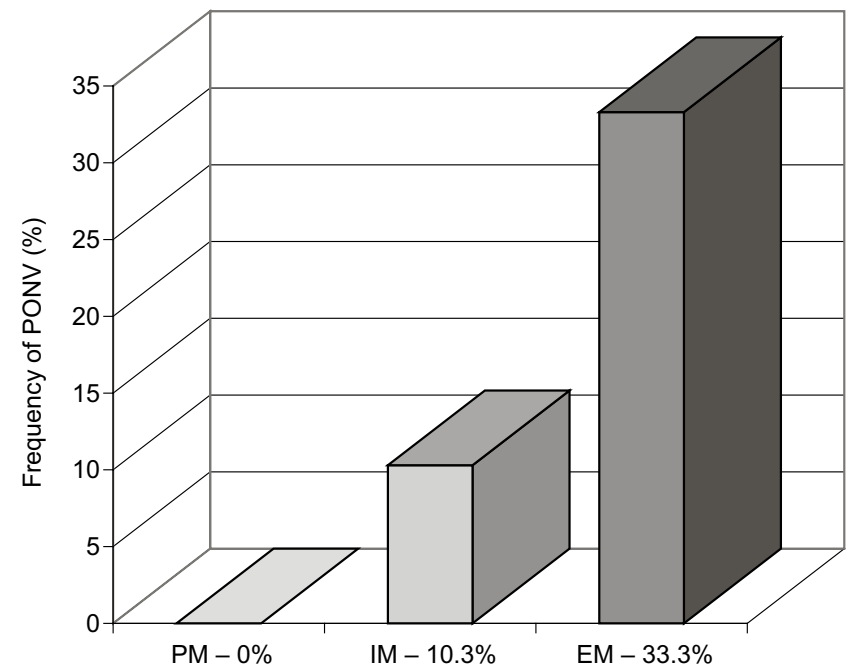

Fig. 1. Percentage of postoperative nausea and vomiting (PONV) episodes among poor metabolizers (PMs), intermediate metabolizers (IMs) and extensive metabolizers (EMs) treated with ondansetron

\section{Discussion}

The evaluation of the metabolic polymorphism of $C Y$ $P 2 D 6$ and the frequency of PONV among surgical patients treated with ondansetron has rarely been reported until now. The antiemetic efficacy of ondansetron has only been studied during cancer chemotherapy. Our results are parallel to the results of Kaiser et al., who analyzed the effects of antiemetic treatment with ondansetron and tropisetron during cancer chemotherapy and revealed that genetically defined UMs of CYP2D6 had a higher frequency of vomiting within the first $4 \mathrm{~h}(\mathrm{p}<0.001)$ and within the period of $5-24 \mathrm{~h}(\mathrm{p}<0.03)$ after treatment than all the other patients; the tendency for nausea was similar. ${ }^{21}$ The results of both studies confirm conclusions of Fisher et al. and Dixon et al. from in vitro studies, endorsing the key role of CYP2D6 in the metabolism of ondansetron, despite the doubts of Ashforth et al. ${ }^{5,22,23}$ The latter questioned the importance of CYP2D6 phenotype in the in vivo metabolism of ondansetron by showing that there was no significant difference in area under curve (AUC), maximal concentration $\left(C_{\max }\right)$, clearance $(C L)$, or half-life time $\left(t_{1 / 2}\right)$ between the 6 PMs and the 6 EMs. ${ }^{23}$

The involvement of the CYP2D6 system in the sensitivity to PONV was further confirmed by Wesmiller et al. and Dong et al. ${ }^{24-26}$ Patients who were classified as PMs had fewer PONV episodes and higher pain scores. These findings suggest variability in CYP2D6's impact on susceptibility to PONV. ${ }^{27}$

Janicki and Sugino suggested that genotyping for CYP2D6 UM polymorphisms (gene multiplications) for PONV or other medications "currently may be prohibitively costly and inconvenient" because "only a small proportion of Caucasians carry the CYP2D6 allele duplication and hence are at risk for PONV treatment failure". ${ }^{28,29}$ The frequency of the UM genotype varies by population, ranging from $1 \%$ to $8 \%$ among Caucasians. ${ }^{14,26}$ Basic, inexpensive genotyping for $C Y P 2 D 6 * N x N, C Y P 2 D 6 * 3$, $C Y P 2 D 6 * 4$, and CYP2D6*5, definitely the most common mutations among Caucasians, could be useful for dividing patients into 2 subpopulations. The combined group of EMs and the rare UMs ( $66 \%$ of the Caucasian population) requires higher doses of ondansetron. The combined group of IMs and PMs (34\%) could be treated with standard doses. The NND is low (3.35), which suggests a relatively high (in comparison with other tests) pharmacoeconomic value for basic CYP2D6 analysis. ${ }^{30} \mathrm{We}$ suggest that this approach is quite affordable and could be clinically useful.

Our results, and those of other studies, strongly suggest that antiemetic treatment with ondansetron could be improved by adjusting the drug dosage according to the patient's CYP2D6 genotype, by using a basic, inexpensive and widely available PCR-RFLP test.

\section{Conclusions}

The antiemetic efficacy of ondansetron in PONV after strumectomy is associated with CYP2D6 metabolism, determined by genotyping for the CYP2D6*1, CYP2D6*3, $C Y P 2 D 6 * 4, C Y P 2 D 6 * 5$, and $C Y P 2 D 6 * N x N$ alleles.

Genetically defined CYP2D6 EMs and UMs present a statistically significant higher risk of PONV than IMs and PMs.

Postoperative nausea and vomiting treatment with ondansetron could be improved by adjusting the drug dosage based on CYP2D6 genotyping, using simple, inexpensive and widely available PCR and PCR-RFLP tests. 


\section{References}

1. Golembiewski JA, O'Brien D. A systematic approach to the management of postoperative nausea and vomiting. J Perianesth Nurs. 2002;17(6):364-376.

2. Kovac AL. Prevention and treatment of postoperative nausea and vomiting. Drugs. 2000;59(2):213-243.

3. Horn CC, Wallisch WJ, Homanics GE, Williams JP. Pathophysiological and neurochemical mechanisms of postoperative nausea and vomiting. Eur J Pharmacol. 2014;722:55-66.

4. Vrabel M. Is ondansetron more effective than granisetron for chemotherapy-induced nausea and vomiting? A review of comparative trials. Clin J Oncol Nurs. 2007;11(6):809-813.

5. Fischer V, Vickers $A E$, Heitz $F$, et al. The polymorphic cytochrome $\mathrm{P}-4502 \mathrm{D} 6$ is involved in the metabolism of both 5-hydroxytryptamine antagonists, tropisetron and ondansetron. Drug Metab Dispos. 1994; 22(2):269-274.

6. Lewis DFV, Ito $Y$, Eddershaw PJ, et al. An evaluation of ondansetron binding interactions with human cytochrome P450 enzymes CYP3A4 and CYP2D6. Drug Metab Lett. 2010;4(1):25-30.

7. Sugino S, Janicki PK. Pharmacogenetics of chemotherapy-induced nausea and vomiting. Pharmacogenomics. 2015;16(2):149-160.

8. Sanwald P, David M, Dow J. Characterization of the cytochrome P450 enzymes involved in the in vitro metabolism of dolasetron. Comparison with other indole-containing 5-HT3 antagonists. Drug Metab Dispos. 1996;24(5):602-609.

9. Hocum BT, White JR, Heck JW, et al. Cytochrome P-450 gene and drug interaction analysis in patients referred for pharmacogenetic testing. Am J Health Syst Pharm. 2016;73(2):61-67.

10. Belle DJ, Singh H. Genetic factors in drug metabolism. Am Fam Physician. 2008;77(11):1553-1560.

11. Abaji R, Krajinovic M. Current perspective on pediatric pharmacogenomics. Expert Opin Drug Metab Toxicol. 2016;12(4):363-365.

12. Zanger UM, Raimundo S, Eichelbaum M. Cytochrome P450 2D6: Overview and update on pharmacology, genetics, biochemistry. Naunyn Schmiedebergs Arch Pharmacol. 2004;369(1):23-37.

13. He ZX, Chen XW, Zhou ZW, Zhou SF. Impact of physiological, pathological and environmental factors on the expression and activity of human cytochrome P450 2D6 and implications in precision medicine. Drug Metab Rev. 2015;47(4):470-519.

14. Gardiner SJ, Begg EJ.Pharmacogenetics, drug-metabolizing enzymes, and clinical practice. Pharmacol Rev. 2006;58(3):521-590.

15. Daly AK, Brockmöller J, Broly F, et al. Nomenclature for human CYP2D6 alleles. Pharmacogenetics. 1996;6(3):193-201.

16. Dahl ML, Johansson I, Palmertz MP, at al. Analysis of the CYP2D6 gene in relation to debrisoquine and desipramine hydroxylation in a Swedish population. Clin Pharmacol Ther. 1992;51(1):12-17.

17. Sachse C, Brockmöller J, Bauer S, Roots I. Cytochrome P450 2D6 variants in Caucasian population: Allele frequencies and phenotyping consequences. Am J Hum Genet. 1997;60(2):284-295.
18. Smith C, Gough A, Leigh P, et al. Debrisoquine hydroxylase gene polymorphism and susceptibility to Parkinson's disease. Lancet. 1992;339 (8806):1375-1377.

19. Lovlie R, Daly AK, Molven A, et al. Ultrarapid metabolizers of debrisoquine: Characterization and PCR-based detection of alleles with duplication of the CYP2D6 gene. FEBS Lett. 1996;392(1):30-34.

20. Steijns LSW, van der Weide J. Ultrarapid drug metabolism: PCR-based detection of CYP2D6 gene duplication. Clin Chem. 1998;44(5):914-917.

21. Kaiser R, Sezer O, Papies A, et al. Patient-tailored antiemetic treatment with 5-hydroxytryptamine type 3 receptor antagonists according to cytochrome P-450 2D6 genotypes. J Clin Oncol. 2002;20(12): 2805-2811.

22. Dixon CM, Colthup PV, Serabjit-Singh CJ, et al. Multiple forms of cytochrome P450 are involved in the metabolism of ondansetron in humans. Drug Metab Dispos. 1995;23(11):1225-1230.

23. Ashforth El, Palmer JL, Bye A, Bedding A. The pharmacokinetics of ondansetron after intravenous injection in healthy volunteers phenotyped as poor or extensive metabolizers of debrisoquine. $\mathrm{Br}$ J Clin Pharmacol. 1994;37(4):389-391.

24. Wesmiller SW, Conley Y, Sereika S, et al. Postoperative nausea and vomiting among women with breast cancer: A genetic analysis of selected polymorphisms of genes of the serotonin pathway. Biology and Control of Nausea and Vomiting 2013 Online Abstracts. http://internationalvomiting conference.org/Program-book.pdf. Pittsburgh, PA: University of Pittsburgh; 2013:63. Accessed 20 January, 2015.

25. Wesmiller SW, Henker RA, Sereika SM, et al. The association of CYP2D6 genotype and postoperative nausea and vomiting in orthopedic trauma patients. Biol Res Nurs. 2013;15(4):382-389.

26. Dong H, Lu SJ, Zhang R, Liu DD, Zhang YZ, Song CY. Effect of the CYP2D6 gene polymorphism on postoperative analgesia of tramadol in Han nationality nephrectomy patients. Eur J Clin Pharmacol. 2015;71(6):681-686.

27. Bell GC, Caudle KE, Whirl-Carrillo M, et al. Clinical Pharmacogenetics Implementation Consortium (CPIC) guideline for CYP2D6 genotype and use of ondansetron and tropisetron. Clin Pharmacol Ther. 2017;102(2):213-218.

28. Janicki PK. Cytochrome P450 2D6 metabolism and 5-hydroxytryptamine type 3 receptor antagonists for postoperative nausea and vomiting. Med Sci Monit. 2005;11(10):322-328.

29. Janicki PK, Sugino S. Genetic factors associated with pharmacotherapy and background sensitivity to postoperative and chemotherapyinduced nausea and vomiting. Exp Brain Res. 2014;232(8):2613-2625.

30. Plumpton CO, Roberts D, Pirmohamed M, Hughes DA. A systematic review of economic evaluations of pharmacogenetic testing for prevention of adverse drug reactions. Pharmacoeconomics. 2016;34(8): 771-793. 